\title{
Aprendizagem em aulas síncronas no Ensino Médio na perspectiva dos discentes
}

\author{
Learning in remote classes in High School in the perspective of students \\ Aprendizaje en clases remotas en el Bachillerato desde la perspectiva de los estudiantes
}

\author{
Rafaela Generozo Balthazar \\ ORCID: https://orcid.org/0000-0001-8241-6816 \\ Universidade Municipal de São Caetano do Sul, Brasil \\ E-mail: generozo.rafaelag@gmail.com \\ Bianca Alves da Silva \\ ORCID: https://orcid.org/0000-0002-7638-0631 \\ Universidade Municipal de São Caetano do Sul, Brasil \\ E-mail: biancaasilva019@gmail.com \\ Carlos Alexandre Felício Brito \\ ORCID: https://orcid.org/0000-0002-0060-8644 \\ Universidade Municipal de São Caetano do Sul, Brasil \\ E-mail: carlos.brito@online.uscs.edu.br
}

\begin{abstract}
Resumo
O objetivo desta pesquisa foi compreender a aprendizagem e o pragmatismo dos discentes em aulas síncronas determinadas pelas Tecnologias Digitais de Informação e Comunicação (TDIC). O delineamento da pesquisa é uma pesquisa exploratória e descritiva. Amostra do tipo de conveniência. Foi realizada uma entrevista em profundidade (semi-estruturada). Foram realizadas as descrições das entrevistas para a construção do Corpus textual. A análise deste Corpus textual foi realizada da seguinte forma: i) análise do trívio dos signos (linguagem - escrita, dialética e retórica) dos entrevistados e ii) análise lexical, com auxílio do software denominado IRAMUTEQ. Foi observado dificuldade inicial na adaptação, por conta da mudança radical que tanto discentes como professores sofreram, porém, atualmente há indícios de adaptação nesta nova situação quando comparado ao começo do isolamento em época de COVID-19. A flexibilidade é o ponto forte das aulas, pois os discentes relatam a praticidade, muito embora eles descrevem que há problemas de conexão e falta de interação entre os discentes-professores e ou discentes-discentes. Algumas mudanças seguem sendo necessárias, por exemplo, oferecer métodos mais eficazes para o melhorar o processo de aprendizado, bem como recursos oferecidos pelas tecnologias digitais de aprendizagem.
\end{abstract}

Palavras-chave: Aprendizagem; Ensino remoto emergencial; Percepção; Ensino médio.

\begin{abstract}
The objective of this research was to understand the learning and the pragmatism of students in remote classes determined by Digital Technologies of Information and Communication (DTIC). The research was an exploratory and descriptive. Convenience type sample. An in-depth (semi-structured) interview was conducted and descriptions of the interviews were carried out for the construction of the textual Corpus. The analysis of this textual Corpus was carried out as it follows: i) analysis of the trivia of signs (language - writing, dialectic and rhetoric) of the interviewers ii) lexical analysis, with the assistance of the software called IRAMUTEQ. Initial difficulty in adapting was observed due to the radical change that both students and teachers underwent, however, there are currently signs of adaptation in this new situation when compared to the beginning of isolation at the time of COVID-19. Flexibility is the strength of the classes, as the students report the practicality, even though they describe that there are problems with connection and the lack of interaction between the students-teachers or students-students. Some changes are still needed to offer more effective methods to improve the learning process, as well as resources offered by DTIC.
\end{abstract}

Keywords: Learning; Emergency remote learning; Perception; High school.

\section{Resumen}

El objetivo de esta investigación fue comprender el aprendizaje y el pragmatismo de los estudiantes en clases sincrónicas determinadas por las Tecnologías Digitales de la Información y la Comunicación (TDIC). El diseño de la investigación es una investigación exploratoria y descriptiva. Muestra de tipo de conveniencia. Se realizó una entrevista en profundidad (semiestructurada). Se realizaron descripciones de las entrevistas para la construcción del Corpus textual. El análisis de este corpus textual se realizó de la siguiente manera: i) análisis de la trivia de signos (lenguaje - escritura, dialéctica y retórica) de los entrevistados y ii) análisis léxico, con la ayuda del software denominado IRAMUTEQ. Se observó dificultad inicial de adaptación, debido al cambio radical que atravesaron tanto estudiantes como docentes, sin embargo, actualmente existen indicios de adaptación a esta nueva situación en comparación con el inicio del aislamiento 
en la época del COVID-19. La flexibilidad es la fortaleza de las clases, ya que los estudiantes reportan la practicidad, aunque describen que existen problemas de conexión y falta de interacción entre los estudiantes-profesores y / o estudiantes-estudiantes. Aún se necesitan algunos cambios, por ejemplo, para ofrecer métodos más efectivos para mejorar el proceso de aprendizaje, así como los recursos que ofrecen las TDIC.

Palabras clave: Aprendiendo; Aprendizaje remoto de emergencia; Percepción; Escuela secundaria.

\section{Introdução}

O processo do ensino-aprendizagem no contexto do COVID-19 tem se mostrado desafiador do ponto de vista do fazer pedagógico do docente no ensino superior (Nascimento, 2011), uma vez que ele deve dominar uma situação didática que nem sempre esteve presente em sua prática profissional, quando comparado aos docentes que já ensinam em situações similares, como por exemplo, no ensino a distância (EaD) (Silva, 2003), porém não temos conhecimento sobre esta situação didática em aulas síncronas, portanto um novo fenômeno se apresenta em nossa realidade (Arruda, 2020).

Neste sentido, há necessidade de um domínio pedagógico mediado pelas Tecnologias Digitais de Informação e Comunicação (TDIC) (Galindo, Sá, Barbosa, Pereira, Henriques \& Barros, 2020), uma vez que a situação trouxe um caráter necessário provocado pelo isolamento social: a comunicação entre os falantes mediada pelas tecnologias digitais (Dos Santos Junior e Silva Monteiro, 2020). Portanto, o isolamento social se configura numa nova ordem para quem o presencia em sua experiência, muito embora está nova ordem traz aos seus atores (docentes-discentes) um novo desafio, ou seja, o de ensinar nesta nova realidade; porém isto já foi delineado, em nossa sociedade contemporânea, pelo processo virtual (Lévy, 2011).

Um ponto que merece atenção neste processo é que, o docente tem o conhecimento teórico necessário que deva ser desenvolvido em sua matéria em que leciona, porém há necessidade de que este conhecimento possa ser apropriado ao discente. Neste processo, de apropriação do conhecimento, o mesmo deve ser mediado pela comunicação entre eles (professor-aluno), de forma que a aprendizagem possa ser significativa crítica (Moreira, 2011; Moreira, 2014) para o discente, pois uma falta na comunicação poderá ocasionar alguns ruídos que poderia afetar o processo de ensino e na aprendizagem (Pereira, Da Silva, Novello, 2018 Rosa, Mendes, Locatelli, 2018; Soto \& Vallori, 2011).

As compreensões destes ruídos se fazem necessários, pois há em hipótese que os docentes e discentes que forem mais adaptáveis (autoeficácia, Bandura, 1986; Meneses, 2010) e pragmáticos (Muraro, 2008), neste novo cenário de ensino e de aprendizagem, poderão regular melhor as condições de lidar com está situação didática que deve ser mediada pelas tecnologias digitais de informação e de comunicação.

O objetivo da pesquisa foi compreender a aprendizagem e o pragmatismo dos discentes em aulas síncronas determinadas pelas tecnologias digitais de informação e comunicação (TDIC). Como específicos determinamos: a) Identificar itens favoráveis e desfavoráveis na adaptação dos discentes no momento da aprendizagem determinada pelas TDIC; b) Verificar como o discente interage com os materiais educativos neste novo cenário; c) Comparar quais materiais educativos podem potencializar o processo de ensino e aprendizagem percebido pelos discentes neste novo cenário.

\section{Material e Método}

Esta pesquisa se caracteriza como uma abordagem qualitativa. Segundo Chizzotti (2006), o foco deste tipo de pesquisa não é a representatividade numérica, mas o enfoque se dá no aprofundamento do grupo social; em nosso caso, dos discentes (discentes) do ensino médio (Educação Básica).

O delineamento da pesquisa se configura como uma pesquisa exploratória e descritiva. O procedimento escolhido para compreensão do fenômeno foi a Entrevista em Profundidade. Em nosso caso, a fonte deste conhecimento foi o discente. E ainda, o objetivo deste procedimento é perceber pelos entrevistados elementos de compreensão de uma situação ou a estrutura de um problema. 
Optamos por fazer uma entrevista semiestruturada. Um ponto importante é que há um modelo, ou seja, um roteiro de base. Este roteiro de base foi construído a partir das bases teóricas apresentadas pelos pressupostos dos Gestos Didáticos (Nascimento, 2011).

A seleção dos entrevistados foi do tipo de conveniência, pois as fontes foram selecionadas pela sua proximidade e ou disponibilidade. Os participantes da pesquisa-ação foram discentes do ensino médio, da região do Grande ABC, de instituições públicas e ou privadas.

Neste momento tão particular de isolamento social, devido a pandemia, ou seja, devido ao COVID-19, realizamos as entrevistas por meio da videoconferência. Respeitadas as características da pesquisa e com o consentimento dos discentes as entrevistas foram gravadas.

Posteriormente a coleta, foram realizadas as descrições das entrevistas para a construção do Corpus textual. O Corpus textual representa a transcrição (decodificação) desprendida das entrevistas. A análise deste Corpus textual foi realizada da seguinte forma:

1. Analisamos, num primeiro momento, o exame da linguagem, denominado por trívio dos signos - gramática, dialética e a retórica (Levy, 2011). Levy (2011, p.81) descreveu que a partir do “[...] continuum dos sons, uma língua isola ou separa fonemas, espécie de elementos primários não significantes. As unidades significantes (palavras ou falas) apresentam-se à análise com sequência de elementos desprovidos de sentido neles mesmos (os fonemas)” [...]. E ele continua a descrever que, “[...] a gramática é a arte de compor pequenas unidades significantes". Portanto, iniciamos pelo exame da escrita (gramatização da fala). Continuando o exame da linguagem, e apoiando-se no mesmo autor, analisamos a dialética apresentada em suas falas (dos discentes). Assim, tentamos verificar o saber raciocinar nesta nova ordem, mediado pelas tecnologias digitais. E, ao final desta análise dos signos tentaremos verificar a retórica deles, portanto verificar em seus discursos o poder de convencimento, quer sejam positivos, negativos e ou neutros, mas necessários nesta nova reorganização do saber-fazer do discente em aulas síncronas, pois se trata de um estudo exploratório.

2. A finalização do Corpus textual teve o auxílio do software denominado IRAMUTEQ (Interface de R pour les Analyses Multidimensionnelles de Textes et de Questionnaires), que tem por finalidade descobrir a informação essencial contida num texto, através de análise estatística textual. Este software foi desenvolvido por Pierre Ratinaud, e para que se possa compreender a análise textual que realiza, é necessário inicialmente explicitar alguns conceitos importantes: 1) Corpus é o conjunto de textos que se pretende analisar. 2) Texto é cada entrevista que compõe o Corpus. Se uma determinada análise diz respeito às respostas de " $n$ " participantes a uma questão aberta, cada resposta será um texto, e teremos "n" textos. 3) Segmentos de texto são partes do texto, na maioria das vezes, do tamanho de três linhas, dimensionadas pelo próprio software. Assim, corpus, texto e segmentos de texto constituem o objeto de análise do IRAMUTEQ (Ratinaud, 2009).

\section{Resultados e Discussão}

Buscamos por meio de pesquisas compreender a qualidade do aprendizado e do êxito na perspectiva dos discentes em aulas síncronas possibilitadas pelo uso das tecnologias digitais de informação e comunicação (TDIC). Inicialmente, procuramos artigos e teses para entender a realidade do Ensino Remoto Emergencial (ERE) na pandemia para os discentes do ensino médio. Com isso, obtivemos uma base teórica do assunto e conseguimos relacionar a pesquisa com as entrevistas. 
Na segunda parte da pesquisa, separamos os voluntários em três dias com diferentes realidades, mas todos entre 15-17 anos que estavam no ensino médio. As entrevistas foram conduzidas por perguntas pré-definidas sobre a adaptação do aluno no ERE, pontos positivos e negativos, materiais facilitadores da aprendizagem, a relação docente-discente e o uso das tecnologias no processo de ensino.

Figura 1. Nuvem de palavras.

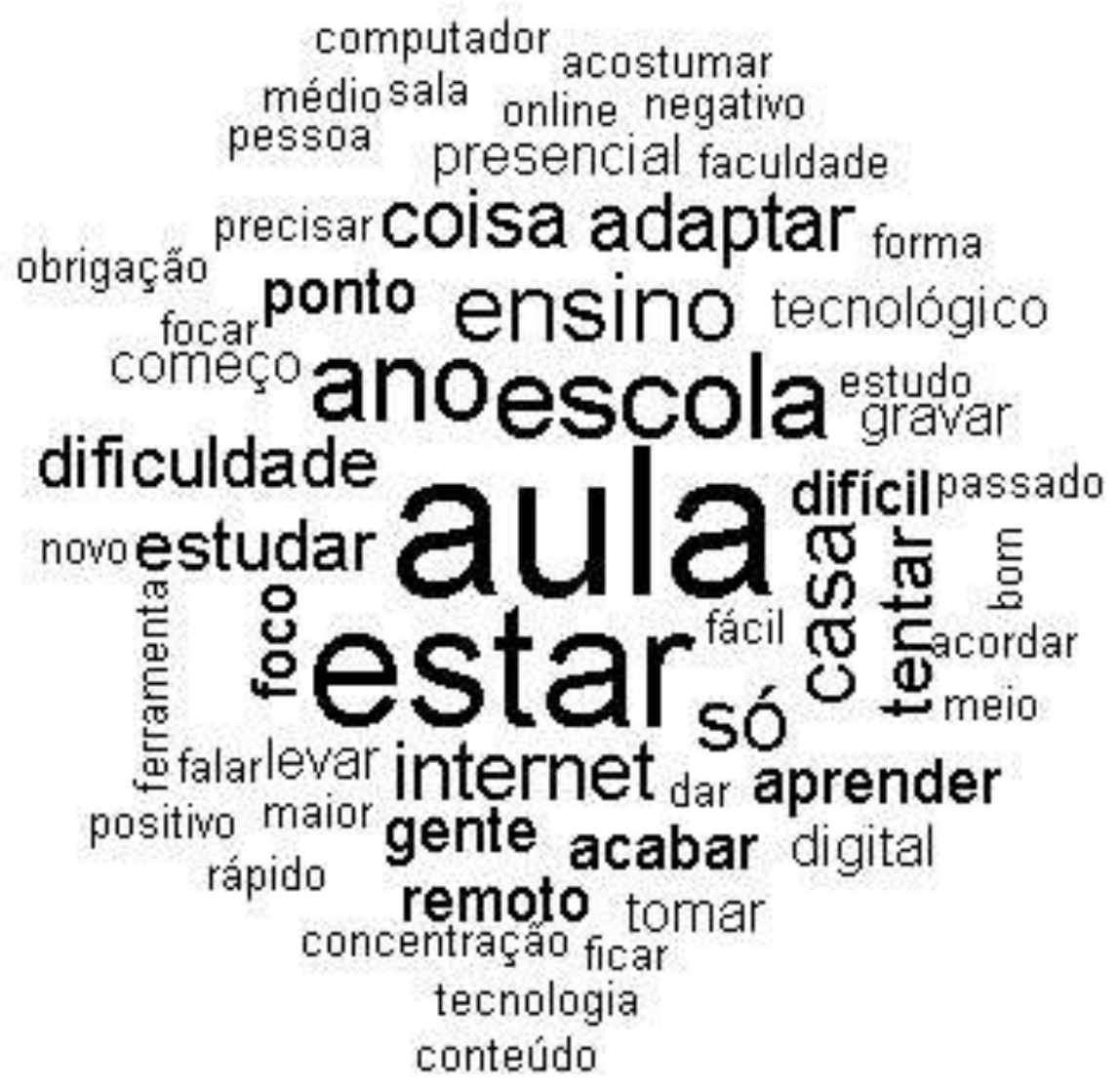

Fonte: Preparado pelos próprios autores no software Iramuteq, Ratinaud, (2009).

A partir das entrevistas foi realizada a análise de conteúdo e, por meio do software Iramuteq, foi criada a nuvem de palavras. Pode-se observar, na Figura 1, o que foi mais citado pelos entrevistados, por exemplo, verificar-se as palavras "aula", "escola", "dificuldade", "adaptar", "estudar", mais centrais, pois elas foram citadas com mais frequência, enquanto as palavras “computador", “tecnologia, "novo", estão mais periféricas na nuvem, uma vez que elas foram citadas com menor frequência. Portanto, podemos inferir que o ERE trouxe dificuldades no processo de aprender durante as aulas remotas, porém foi um processo necessário de adaptação com a tecnologia, em outras palavras, uma nova situação para aprender um determinado conteúdo no momento da escolarização. A nuvem de palavras é um recurso visual que ajuda na análise das entrevistas e resume os pontos principais a serem discutidos em nossa pesquisa. 
Figura 2. Gráfico de similitude.

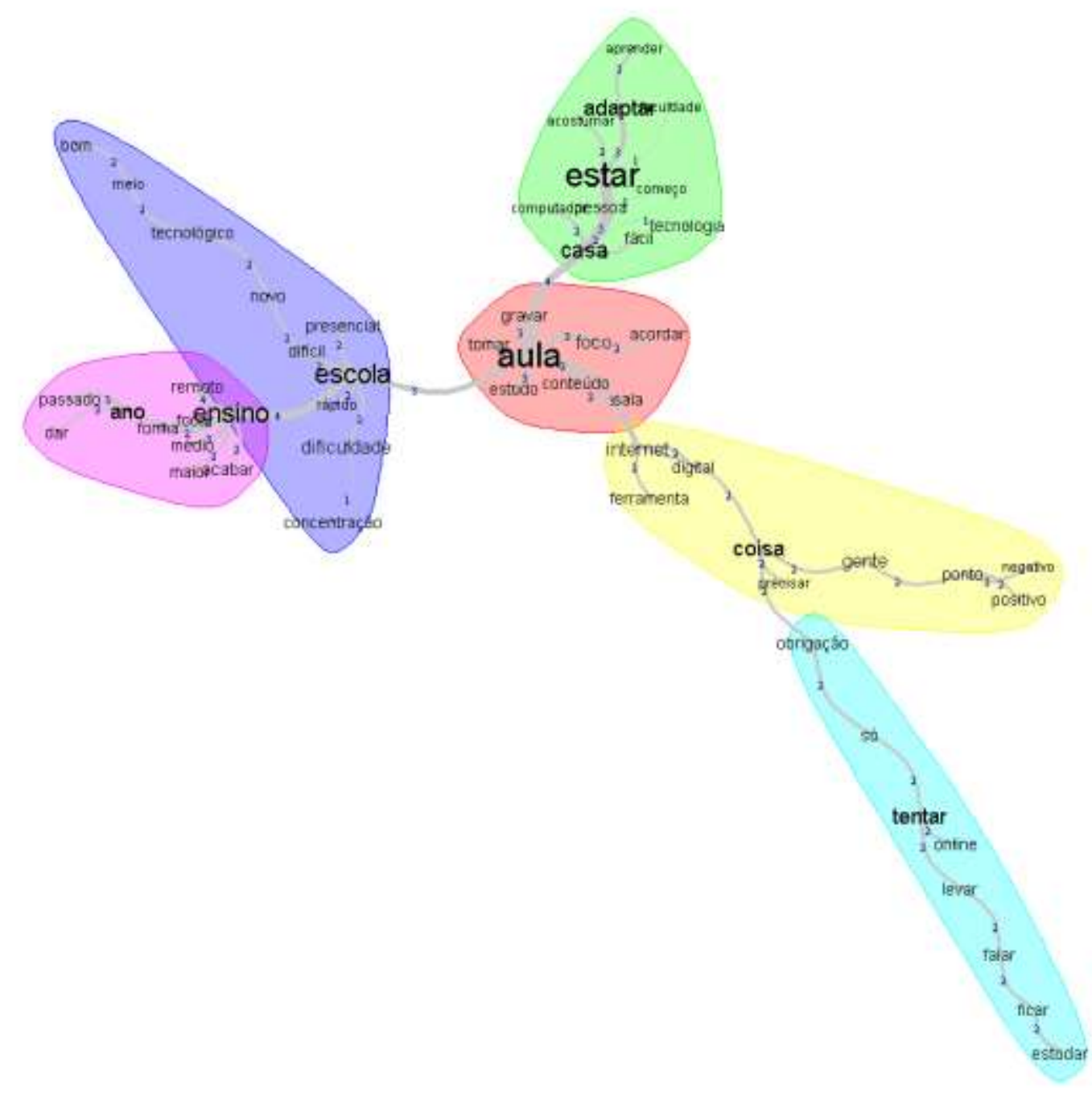

Fonte: Preparado pelos próprios autores no software Iramuteq. Ratinaud, (2009).

A Figura 2 mostra grupos de palavras (Clusters) que geram algum sentido e que se relacionam com o assunto estudado. Um exemplo, quando observamos as palavras "escola", "presencial”, "meio", "tecnológico", "dificuldade”, “concentração", "ensino", "médio"; conseguimos identificar o contexto e, consequentemente, entender que a escola não é mais um espaço físico presencial, mas agora as aulas são aplicadas por meios tecnológicos, o que dificultou a concentração dos discentes do ensino médio.

A seguir, optamos para apresentar os nossos achados dividindo a nossa apresentação por meio de subitens (em destaque) que possam dar maior sentido às narrativas dos participantes desta pesquisa.

\section{Adaptação dos discentes: itens favoráveis e desfavoráveis}

A pesquisa mostrou que, de maneira geral, houve dificuldades na adaptação inicial por conta da mudança causada pelo isolamento social. Porém, atualmente, estão lidando melhor com essa situação e os motivos mais relatados foram por costume e aceitação, maneiras diversas para fluírem melhor nos estudos. Uma minoria divergiu da opinião dizendo que, foi até rápida a adaptação por conta da flexibilidade do ERE. 
Dos pontos positivos do ERE diz respeito ao fato de estar em casa, pois abriu caminho para maior liberdade e praticidade aos estudantes durante as aulas. E ainda, pode-se perceber que o acesso era imediato, de forma rápida para pesquisa.

“Estou vendo uma matéria e não entendi, posso dar um Google rapidinho na aula mesmo” - I.F.G. do $2^{\circ}$ ano E.M

O fato de tudo ser online trouxeram aos participantes o descobrimento de novas ferramentas tecnológicas digitais que facilitaram o processo de estudo, ou seja,

“Eu pude descobrir novas ferramentas tecnológicas, que mesmo sendo da minha época eu não usava muito". - S.S. do $2^{\circ}$ ano E.M

Portanto, podemos perceber que é este novo fazer da aula digital trouxe aos discentes uma boa oportunidade de aprendizagem, assim como na interação no processo da construção do conhecimento.

"Eu acho que isso é muito bom porque fez a escola se reinventar de jeito que nunca um diretor pensaria, em usar a internet, usar meios tecnológicos, usar tablet para ensinar discentes. Então acho que isso abre uma nova porta para educação que talvez no futuro, ou até mesmo agora, seja benéfico para a gente”- P.C.G.M. do $2^{\circ}$ ano E.M

Relatos positivos e que nos chamaram a atenção foi o fato deles relatarem sobre o silêncio de estar em casa ter ajudado na concentração, ter mais tempo para estudar, em outras palavras, aprender a aprender. Destacaram em poder fazer anotações digitais, com possibilidades de fazer provas com consulta e ter uma melhor organização em relação às atividades, pois elas estão sempre anotadas em plataformas digitais como o Google Classroom.

No que diz respeito aos aspectos negativos observamos que a qualidade da internet, a conexão, tanto do aluno quanto do professor, às vezes falha e atrapalhava a aula, assim como a falta de interações presenciais. Castaman e Rodrigues (2020) descrevem em sua pesquisa sobre como a falta de interação e comunicação entre discentes e professores torna o processo de aprendizagem ainda mais complicado e aumenta a dificuldade em manter o foco,

“pra mim o ponto positivo é poder estar no conforto da minha cama [...] Mas também é um ponto negativo porque atrapalha meu foco, eu não tomo nota, outro ponto negativo é poder pegar meu celular e andar pela casa” - M.E.S. do $2^{\circ}$ ano E.M

Percebemos no relato acima a falta de disciplina e motivação, assim como a dificuldade em manter uma rotina, como destacado

“sobre acordar em cima da hora e não ter mais rotina, acaba com a disposição pro resto do dia também”. - S.S. do $2^{\circ}$ ano E.M

Outro ponto percebido na pesquisa foi a condição que cada pessoa tem para orientar-se no ensino e, com efeito, isso poderia ser positivo ou negativo, por exemplo, pessoas com boas condições econômicas e acesso à internet para manter sua qualidade na aprendizagem. 
"Aqui em casa eu divido o computador com minha irmã que faz faculdade, toda vez que tem notificação da faculdade eu passo pra ela o computador, e tentar ver aula pelo celular me faz perder o foco". - G.M.O. do $2^{\circ}$ ano do E.M

Isso é um indício de falta de oportunidades, pois atualmente é indispensável um meio digital, pelo menos razoável, para assistir às aulas de modo online e, sem isso, a educação tem prejuízo (Appenzeller, 2020).

\section{Relação discente e materiais educativos nas aulas síncronas}

Durante as aulas remotas os materiais comuns de estudo como lousas e apostilas têm tido pouco uso, pois foram substituídos ou adaptados. A internet oferece diversas plataformas ou ferramentas que podem ser usadas nesse processo de ensino para promover a aprendizagem.

Jogos e quizzes organizados pelo Kahoot, Mente Meter e Socrative foram utilizados com eficiência durante as aulas, uma vez que essas atividades motivaram a participação e o interesse dos discentes pela aula. Um artigo publicado sobre gamificação e educação (Alves, 2008) tratou exatamente sobre os estímulos e benefícios que os jogos, se bem usados, podem acrescentar na aprendizagem. $\mathrm{O}$ que corroborou com a opinião dos discentes.

Outras ações desenvolvidas pelos docentes e que potencializaram o entendimento dos discentes foram telas compartilhadas, como o Jamboard, músicas e vídeos, sejam sobre o conteúdo ou só para entretenimento, assim como as dinâmicas em grupos durante as aulas com foco maior em resolução de exercícios.

Sabendo como usar essas novas ferramentas para ensinar, os professores podem conseguir bons resultados engajando cada vez mais os discentes no processo de aprender. Mas, percebemos alguns fatores, além dos materiais educativos, que interferem diretamente no aprendizado do aluno, como sua condição social e financeira, sua estratégia de adaptação às aulas síncronas e o método usado pelo docente.

Assim, há necessidade de os professores usarem ferramentas da internet e criar um perfil da turma (Garcia, 2020) para aplicar um método de ensino que possam promover melhores resultados. Os discentes devem buscar qual poderia ser a melhor forma de se adaptar ao ERE, como criar uma rotina, buscar entender como se aprende, fazer listas de afazeres para se organizar o seu tempo de estudo, anotar com canetas coloridas, fazer resumos digitais com recursos da web, usar as ferramentas oferecidas como aulas gravadas para rever os conteúdos, estudar por diversos canais da internet e revisar os conteúdos em outro momento, uma vez que as aulas eram gravadas.

\section{Modelo de estudo e compreensão durante e após o ensino remoto}

Encontramos no uso TDIC consequências satisfatórias para os discentes, sejam elas pelas plataformas ou recursos da web ou associadas a liberdade e praticidade. Um exemplo disto é a Sala de Aula Invertida "[...] por ser um Ensino Híbrido (EH) como a modalidade educacional adequada para combinar aulas presenciais e online."(Oliveira; Corrêa; Morés, 2020 p.7).

A aula gravada foi um recurso destacado na pesquisa, pois os discentes poderiam suprir as dúvidas em outro momento. Um fato interessante é que eles começaram a criar suas próprias estratégias de se organizarem no seu aprendizado.

\section{Considerações Finais}

De acordo com nosso objetivo que foi compreender o aprendizado dos alunos do ensino médio por meio da tecnologia durante o ensino remoto, concluímos que:

- Na fase inicial do Ensino Remoto Emergencial foi a que apresentou maior dificuldade de adaptação 
- Os pontos fortes são a flexibilidade e a praticidade de estar em casa

- As maiores dificuldades são os problemas de conexão, a baixa interação e a falta de recursos

- Mudanças são necessárias, aproveitando novos recursos digitais e métodos de aprendizado

- Consideramos como limitações em nossa pesquisa a falta de estudos que possam corroborar na discussão deste fenômeno

- Assim, consideramos de extrema relevância e necessidade termos mais atenção no que diz respeito a temática, uma vez que as competências digitais se fazem necessárias na atualidade, assim como as desigualdades sociais e econômicas que podem influenciar este processo de aprendizagem.

Levando em conta os nossos achados e os novos desafios no campo do ensino e da aprendizagem, no campo da educação, acreditamos que futuros trabalhos devem analisar como o Ensino Remoto Emergencial (ERE) se encontra nesta fase nova da pandemia, uma vez que o retorno as aulas estão sendo realizadas na sua forma presencial e parte delas na forma online e, em certa medida, poderia caracterizar o ensino híbrido. Enfatizamos que, foi possível observar que há pouco interesse da comunidade científica em pesquisar e publicar tendo como contexto o ensino médio, o que poderia ser relevante para entendimento e compreensão para orientar as políticas educacionais. Um ponto a ser destacado, em nossa análise, é possibilitar novas pesquisas com o olhar nas dificuldades das pessoas com deficiências, quer sejam físicas, sensoriais, dentre outras, durante o ERE.

\section{Agradecimentos}

A pesquisa desenvolvida no Programa de iniciação Científica da USCS teve o auxílio do tipo de bolsa de Iniciação Científica Júnior - CNPq.

\section{Referências}

Alves, L. R. G. (2008). Games e educação - a construção de novos significados. Revista Portuguesa De Pedagogia, (42-2), 225-236. https://doi.org/10.14195/1647-8614_42-2_12

Appenzeller, S., Menezes, F. H., Santos, G. G. d., Padilha, R. F., Graça, H. S., \& Bragança, J. F. (2020). Novos Tempos, Novos Desafios: Estratégias para Equidade de Acesso ao Ensino Remoto Emergencial. Revista Brasileira de Educação Médica, 44(suppl 1). https://doi.org/10.1590/1981-5271v44.supl.120200420

Arruda, E. P. (2020). Educação Remota Emergencial: elementos para políticas públicas na educação brasileira em tempos de Covid-19. EmRede - Revista De Educação a Distância, 7(1), 257-275. Recuperado de https://www.aunirede.org.br/revista/index.php/emrede/article/view/621

Heffernan, C. J. (1988). Social foundations of thought and action: A social cognitive theory, Albert Bandura Englewood Cliffs, New Jersey: Prentice Hall, 1986, xiii + 617 pp. Hardback. US\$39.50. Behaviour Change, 5(1), 37-38. https://doi.org/10.1017/s0813483900008238

Castaman, A. S., \& Rodrigues, R. A. (2020). Educação a distância na crise do COVID - 19: um relato de experiência. Research, Society and Development, 9 (6), e180963699. https://doi.org/10.33448/rsd-v9i6.3699

Chizzotti, A. (2003). Uma pesquisa qualitativa em ciências humanas e sociais: evolução e desafios. Revista Portuguesa de Educação, 16 (2), 221-236. https://www.redalyc.org/articulo.oa?id=37416210

Santos Junior, V. B. dos, \& Monteiro, J. C. da S. (2020). Educação E Covid-19: As Tecnologias Digitais Mediando A Aprendizagem Em Tempos De Pandemia. Revista Encantar, 2, 01-1. https://www.revistas.uneb.br/index.php/encantar/article/view/8583

Galindo Neto, N. M., Sá, G. G. d. M., Barbosa, L. U., Pereira, J. d. C. N., Henriques, A. H. B., \& Barros, L. M. (2020). Covid-19 And Digital Technology: Mobile Applications Available For Download In Smartphones. Texto \& Contexto - Enfermagem, 29. https://doi.org/10.1590/1980-265x-tce-2020-0150

Lévy, P. (1996). O que é o Virtual? Editora 34, 157p. https://doi.org/10.1590/S0100-19651997000200018

Meneses, P. P. M., \& Abbad, G. d. S. (2010). Construção e validação de um instrumento para avaliar auto-eficácia em situações de treinamento, desenvolvimento e educação de pessoas. Psicologia: Reflexão e Crítica, 23(1), 121-130. https://doi.org/10.1590/s0102-79722010000100015

Moreira, M. A. (2011). Aprendizagem significativa: a teoria e textos complementares. Editora Livraria da Física. https://www.livrariadafisica.com.br/detalhe_produto.aspx?id=102563\&titulo=Aprendizagem+Significativa:+a+teoria+e+textos+complementares+ 
Research, Society and Development, v. 10, n. 12, e565101220879, 2021

(CC BY 4.0) | ISSN 2525-3409 | DOI: http://dx.doi.org/10.33448/rsd-v10i12.20879

Moreira, M. A. (2014). Modelos científicos, modelos mentais, modelagem computacional e modelagem matemática: aspectos epistemológicos e implicações para o ensino. Revista Brasileira de Ensino de Ciência e Tecnologia, 7(2). https://doi.org/10.3895/s1982-873x2014000200001

Muraro, D. N. (2008). A importância do conceito no pensamento deweyano: relação entre pragmatismo e educação [Published Version, Universidade de São Paulo]. http://www.teses.usp.br/teses/disponiveis/48/48134/tde-02022009-121312/

Nascimento, E. L. (2011). A dupla semiotização dos objetos de ensino -aprendizagem: dos gestos didáticos fundadores aos gestos didáticos específicos. Signum: Estudos da Linguagem, 14(1), 421. https://doi.org/10.5433/2237-4876.2011v14n1p421

Oliveira, R. M. O., Corrêa, Y. C., \& Morés, A. M. (2020). Ensino remoto emergencial em tempos de covid-19: Formação docente e tecnologias digitais. Rev. Int. de Form. de Professores (RIFP). Published. https://periodicoscientificos.itp.ifsp.edu.br/index.php/rifp/article/view/179/110

Pereira, F. D., Santos da Silva, L. M., \& Novello, T. P. (2018). A Relação Entre a Formação Docente e o Tecnostress. RELACult - Revista Latino-Americana de Estudos em Cultura e Sociedade, 4. https://doi.org/10.23899/relacult.v4i0.721

Ratinaud, P. (2009) IRAMUTEQ: Interface de R pour les Analyses Multidimensionnelles de Textes et de Questionnaires [Computer software]. Disponível em: $<$ http://www.iramuteq.org >.

Rosa, D.L, Mendes, A.N.F. \& Locatelli, A.B. (2018). A formação da identidade docente na licenciatura em química e suas relações com a aprendizagem significativa a partir da análise do modelo de ensino de Gowin. Revista Práxis, 10(20), 147-160.

Silva, M. (2003). Educação online: teorias, práticas, legislação, formação corporativa. Edições Loyola. https://www.livrarialoyola.com.br/produto/educacaoonline-teorias-praticas-legislacao-formacao-corporativa-459294

Soto, B. D. G., \& Vallori, A. B. (2011) UVE de Gowin instrumento metacognitivo para un aprendizaje significativo basado en competencias. IN. Investigació $i$ Innovació Educativa i Socioeducativa, 3(1), 51-62. 